\title{
A Review: Artificial Intelligent Approach for Enhancing Adaptability in an Adaptive E-Learning Environment
}

\author{
M.P.L. Perera
}

\begin{abstract}
Adaptive e-learning the aim is to fill the gap between the pupil and the educator by discussing the needs and skills of individual learners. Artificial intelligence strategies that have the potential to simulate human decision-making processes are important around adaptive e-Learning. This paper explores the Artificial techniques; Fuzzy Logic, Neural Networks, Bayesian Networks and Genetic Algorithms, highlighting their contributions to the notion of the adaptability in the sense of Adaptive E-learning. The implementation of Artificial Neural Networks to resolve problems in the current Adaptive e-learning frameworks have been established.
\end{abstract}

Keywords: adaptive e-Learning, Artificial Intelligence techniques, Bayesian networks, fuzzy logic, Genetic Algorithms, Neural Networks.

\section{INTRODUCTION}

$\mathrm{T}$ he essence of secondary education has dramatically changed since 2000. The participation rate has increased significantly, generating substantial diversity both among the scope and thus the student population of the programs offered. A diverse range of students must care for classrooms which mostly demand that they pay for quality teaching and should receive it. In consequence, universities seem to have more intention than they had ever done before to improve education and maintain quality assurance. Adaptive learning or adaptive teaching seems to be a method of obtaining students with personalized instructional material based on their unique learning capabilities. It is, in essence, the opportunity to provide customized AI services in educational and corporate settings. The learning platform that uses computer algorithms, such as Artificial Intelligence, and is trained to consider the strengths, limitations, learning styles and abilities of students before providing them with the required learning materials and tools. There are some key concepts to bear in mind when talking about adaptive learning technology:

Manuscript received on March 02, 2021.

Revised Manuscript received on March 08, 2021.

Manuscript published on April 30, 2021.

* Correspondence Author

M.P.L.Perera*, Department of Software Engineering, Faculty of Computing and Technology, University of Kelaniya, Dalugama, Sri Lanka. Email: poornima_2019@kln.ac.lk

(C) The Authors. Published by Blue Eyes Intelligence Engineering and Sciences Publication (BEIESP). This is an open access article under the CC BY-NC-ND license (http://creativecommons.org/licenses/by-nc-nd/4.0/)

- The standard of the educational material used.

- The capacity of the AI-based platform to define, evaluate and change student progress.

- Monitoring improvement, assessing success, and leveling based on results

In this regard, there is also an equally common idea of adaptive e-learning that focuses mostly on providing online students with similar experience.

Biological evolution, standards of living, the environment all differ from the students' perspective and are critical to the student's learning period. When it comes to education, the traditional notion of a single classroom or one-size-fits-all is rightly losing its luster [1]. People are different, and then no one learning style is sufficient for all. This is where technology, particularly AI, can help to make content that meets the student's needs, either in schools or even in corporate settings. Together with technological evaluation and AI, data on the learning speed and abilities of individual students can be obtained cost-effectively and shared to learning environment enjoyable, fun, and attractive.

Look at the example of Singapore-based Vere360, which uses Artificial Intelligence and VR provide academic excellence on social and economic issues and professional development. The platform partners with multiple content partner clients to create educational content that students (school and vocational) can access via a Virtual World Educational Application[2].

Another notable example of AI-based Chatbot in education would be that of Botsify, a chatbot that tests students by showing footage, videos, texts on a particular subject and responding to questions.

E-learning can be built in 2 ways when one form of e-learning is conceived as a synchronous e-learning style of learning, while the other is conceived in a self-speed, asynchronous e-learning, which is shown in figure 1 [3]. Adaptive learning is a new tendency in e-learning, which aims to narrow the difference found in conventional e-learning frameworks by adapting the delivery of educational resources to the educational approach of every single individual [4]. An Adaptive e-Learning System (AES) be made up of three(03) different models; a Student model, a Domain model and an Adaptation model [5]. The student model conjointly remarked because the learning model or the user model, is contains all student data. The Domain model contains the course content to support reconciling course delivery. It acts as an information repository that consists of topics, contents,

Blue Eyes Intelligence Engineering

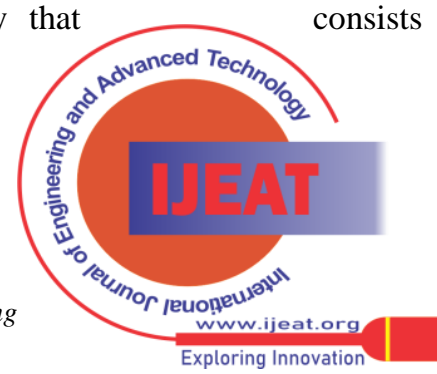




\section{A Review: Artificial Intelligent Approach for Enhancing Adaptability in an Adaptive E-Learning Environment}

pages or nodes and navigation links associated with the look structure of the portrayed information and therefore the reconciling model combines with the reconciling theory of an AES by combining the domain model with the coed model.

It defines what are often tailored and the way and once it's to be tailored [6]. Efficiency and effectiveness of the AES varies depending on the methodology employed to gather information about the educational needs and traits of the students, as well as how this information has been processed to improve an intelligent and adaptive learning perspective [7].AES emphasizes the importance of individual differences among the students when they attempt to model an ideal e-Learning environment, concentrating on the identification and meeting their personal educational demands. The ideas of Artificial Intelligence are of considerable importance in the development of some sort adaptive e-Learning environment because they are able to mimic the decision-making processes adopted by humans [8]. The paper determines the Artificial Intelligence attitude to effective education in the adaptive e-learning context.

Throughout paper, the article provides a collection of issues related to the adaptive training method and related computing strategies, their benefits and drawbacks, or the value of victimization of these techniques to build smarter and much more economical learning environments.

The current COVID-19 pandemic situation makes it impossible for even a smart classroom. Thus, launched an e-learning content development platform to support distance learning in Sri Lanka.

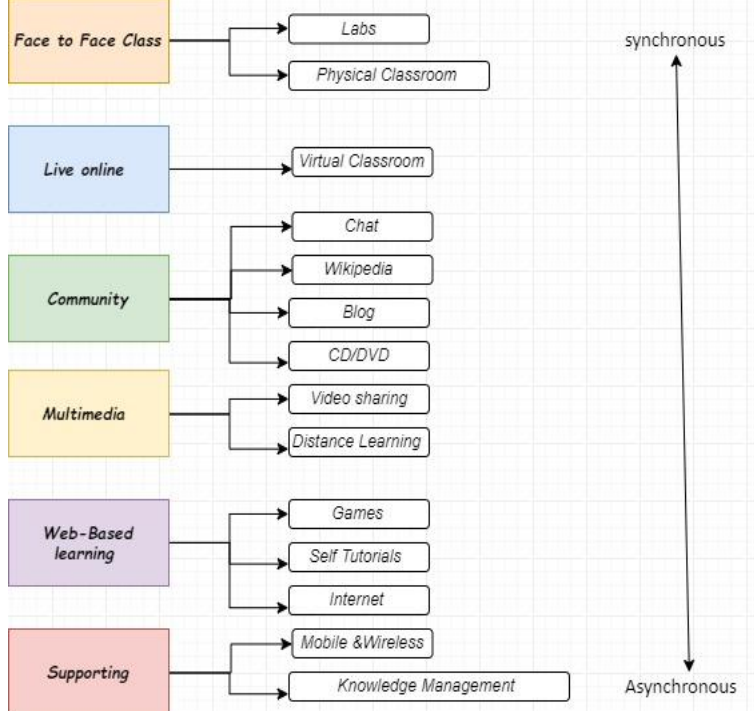

Figure I Asynchronous and synchronous learning settings.

The author will give a summary of several recent issues related to the adaptive education system in Section 2. Section 3 offers a description of the artificial intelligence approaches used by adaptive training systems. Finally, current suggestions and a suggestion for future study.

\section{REVIEW OF RECENT AI TECHNIQUES FOR ADAPTIVE EDUCATIONAL SYSTEMS}

With the advent in education technology, the new generation of learners has improved access among each device as well as the network. Over the last few years, the idea of adaptation in the sense of learning has become an important subject of study. The research has shown that the implementation of adaptation would provide a much better learning experience, because learners will understand and provide methodological knowledge in a very alternative way. Mostly with advances in teaching technology, in particular the conception of e-learning, it is crucial to consider the training vogue and desire of learners for new augmented reality[9].

Adaptive learning, a new method based on AI, will be more effective than a traditional e-Learning system in which It adapts information and overall contact structures to the users and their knowledge and behaviors [10].

Therefore, these data could be used to build an adaptive learning environment effectively. The nonheritable information can then be wont to build adjustive learning environments effectively and used. Such student models and information will be employed in two (2) separate the approaches once they need been collected. the primary is to coach the pedagogy of the integrated education program instructed by specialists and design engineers. The second is that the complicated capability of the program to be told itself from the actions of teachers or students[7]. During lifelong learning, these coping skills can benefit both learners and programs.

Pedagogical data mining and learner analytics are two key areas of overlap that might be extremely important for the development of all these capabilities. Models of artificial intelligence are also useful in achieving certain capacities, as they would be able to learn and mimic the mechanism of making human decisions[11].

Preparing for university admissions, for example, is never easy, particularly for students who do not have the means (financial/technology) or access to quality resources. To promote this, BioBeyond has built an Interactive Learning Framework for the University-Entry Biology Course. The online course consists of eight units and the application will provide input on which parts the student requires to operate. Thus, the current and relevant issues towards digital educational environments, for example the massive open online courses (MOOCs), educational data mining, learner analytics, and relevant artificial intelligence techniques, necessary to be examined and discussed in far more depth.

\section{A. MASSIVE OPEN ONLINE COURSES (MOOCS)}

MOOCs was the trend founded in 2008. To some extent open learning approach has recently become popular [12]. There are two features in MOOC: free of charge and accessible to all users[13]. MOOCs were recently made accessible for learning through several leading colleges and universities such as Stanford as well as in Harvard. There can be thousands to millions of users who might be enrolled in any course, this is many individuals. The key task for MOOCs would be to obtain enormous data sets, deriving from the experiences among students with their learning environments to generate insights into adaptive human learning.

According to [14], The number of students enrolling in massive open-line courses is extremely drop-out rates and hence the graduation rates in such are less than $13 \%$.

Published By:

Blue Eyes Intelligence Engineering DOI:10.35940/ijeat.D2297.0410421

Journal Website: www.ijeat.org

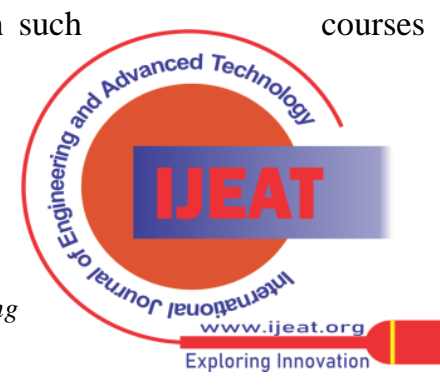


The option may be to change education based on the student's behavioral analysis. Interaction research is not merely beneficial on university grounds; it enables students to obtain feedback on their accomplishments and styles of learning[15]. A comprehensive research on MOOC artificial intelligence and data mining applications has already been issued by Fauvel and $\mathrm{Yu}[16]$.

\section{B.MINING AND OPTIMIZATION FOR EDUCATION}

According to the Dozens different Open-source Learning Management Systems (LMS) are available as examples of ATutor, OpenSWAD, Moodle and ILIAS also learning portals such as Jury`s Inn, Vaillant or massive open online learning which may provide e-learning lessons. These courses highlight a huge amount of data available as a compiled form. The personal attributes and performance evaluation of the student dictate every stage of the process. This data is analyzed through two research disciplines: Learning Analytics (LA) and Educational Data Mining (EDM)[11].

The International academic processing Society, EDM is outlined as a replacement field of study aimed toward making ready techniques for the exploration of specialized kinds of info obtained from the education sector and so the opposite hand, they delineated EDM because of the appliance of these techniques to strengthen the understanding of students and so the atmosphere throughout that they acquire information. As per the Society for Learning Analytics analysis, Learning Analytics (LA) is characterized as collecting, quantifying, analyzing and notifying student-related info regarding their traits, while the coaching method area unit typically well understood and increased and along with the atmosphere throughout that it happens[17].

If a continuous watch is held on both the students ' results, then student experiencing difficulties in the understanding the educational material could be identified in the earliest instance and this can also help to distinguish particular sections of the course that trigger a greater difficulty. When suitable instruments are not available then the entire process is more complicated and may take more time. Students will have the facility to be directed by the appropriate resources in alignment with their expectations and desires, motivation, and success, they will be able to visualize the learning outcomes in graphic form and see where they rank with fellow members of the class, as well as visualize actions and efficiency in the sense of co-education activities.

The key barrier to the effective use of LA and EDM approaches are limited understanding and expertise, a significant number of educators and experts lack knowledge of both realistic and theoretical principles about the correct use of certain techniques. Also, unable to properly interpret the data and correctly discern the inferences or come to a decision on the steps that can be taken. To find a solution to this issue, efforts must be made to create a positive atmosphere for each other and develop a data-driven approach [18] on the subject of education and to list the surveys and visions conducted throughout the framework of learning analytical findings and educational data mining and the application to education objectives with the development of adaptive e-learning courses[18]-[20].

\section{STRATEGIES OF EDUCATION DATA MINING}

The two methods that DM primarily employs are AI (primarily machine learning) and statistical instruments. Two specific categories which can be categorized in DM methods is shown in figurer 2 .
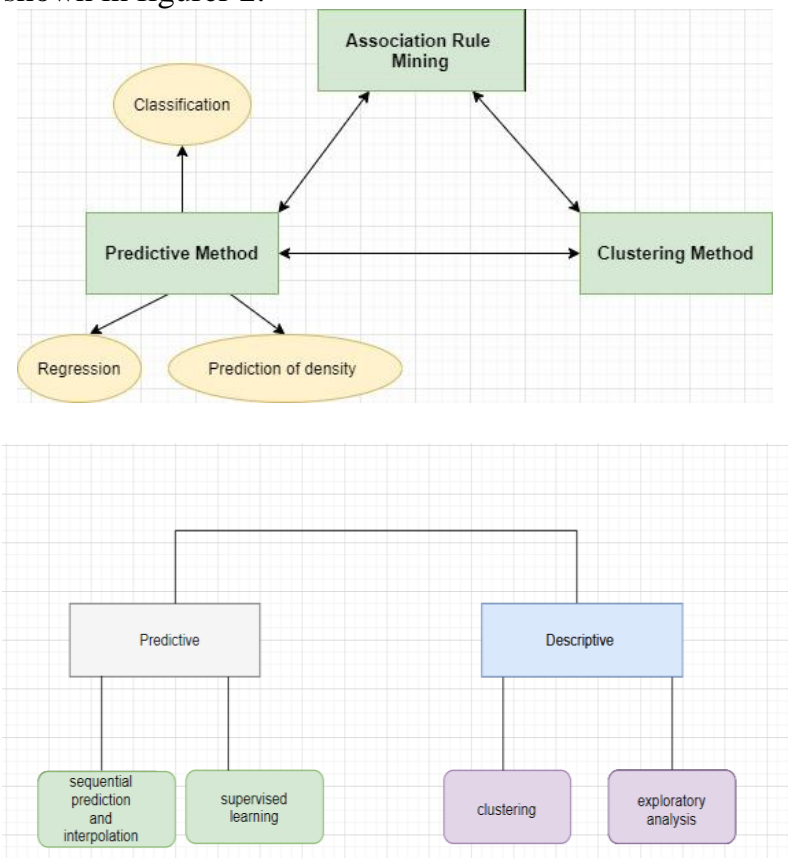

Figure II Educational data Mining techniques

\section{ARTIFICIAL INTELLIGENT STRATEGIES FOR ADAPTIVE E-LEARNING}

Adaptive education systems aim to optimize the overall learning approach to accommodate the students ' needs[21]. It is therefore important to properly define the student's profiles and models, considering the performance, skills, and characteristics of their students. The required knowledge must be used and improved to enhance the adaptive learning environment. AI solutions are considered useful tools, thus, adept of generating and replicating processes of decision-making [8]. AI technologies, including Fuzzy Logic (FL), Decision Tree, Bavarian Networks, Neural Networks, Hidden Markov Models are all used in Adaptive education systems and are dedicated to AI policy, as well as adaptive learning. AI methods in adaptive education systems are used in many forms. The AI methods are being used to encourage the completion of the assessment process such that the course material can be adapted to the needs of each learner and many of them are used to learn from either the scholar programs to adapt the approved computer programs [8], [22], [22]-[24].

In a model of lifelong learning, the learning models created from student behaviors. Consequently, the implementation of an integrated education system focused on knowledge of how learners interact with learning environment in understandable and conceptual white-box models.

Essential in guiding the adaptation approach to the needs of learners, and in understanding how learning is carried out.

Published By:

Blue Eyes Intelligence Engineering

\& Sciences Publication

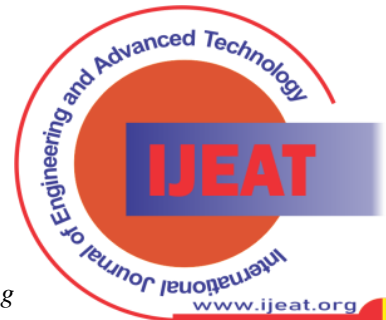

(c) Copyright: All rights reserved. 


\section{A Review: Artificial Intelligent Approach for Enhancing Adaptability in an Adaptive E-Learning Environment}

Examples of AI Methods are Fuzzy Logic (FL), decision trees, neural networks, genetic algorithms, and Markov models, can handle rational decision-making's inherent ambiguity and are groundbreaking approaches that can tackle interpretation, confusion, and partial reality.

AI techniques are useful in this regard for many reasons, along with the ability to improve and mimic human decision-making process and the development of automated and realistic teaching-learning models[25].

\section{A. FUZZY LOGIC}

According to Zadeh (1965), it gradually evolved into a common and efficient user modelling technique, because it could imitate human reasoning. Fuzzy logic could be used as an extension of that same standard set model [26]. The Fuzzy Logic System (FLS) consists of four (04) stages (as shown in Figure III): fuzzifier, rule base, inference engine and defuzzifier.

The Fuzzy guidelines reflect learning-teaching actions within a human-readable and language-specific. Its simplicity makes them ideal for easy evaluation to clarify the purpose and process of certain combinations of input-actuated similar rules where a certain set of output conclusions have been made.

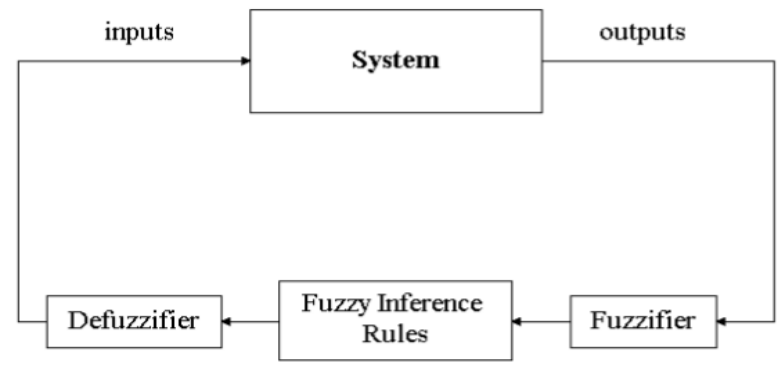

Figure IV Fuzzy Logic Controller [27]

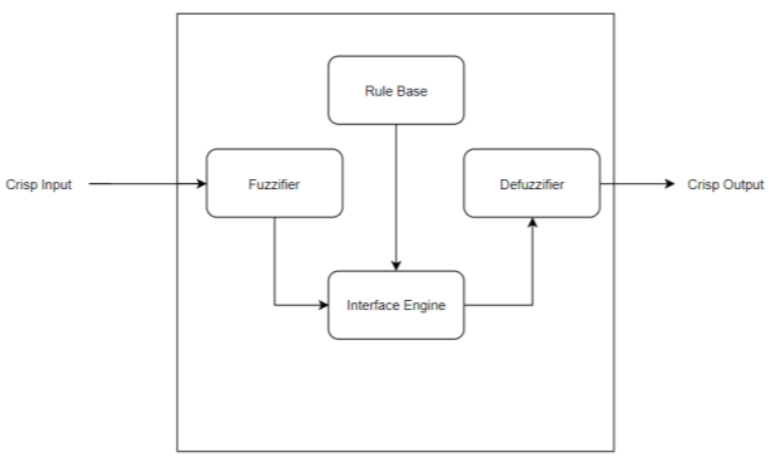

Figure V Overview of a Fuzzy Logic System [28]

A new mechanism and evolution of fuzzy systems could be defined as type 2 FLSs, in which type 2 fuzzy sets express digital and semantic. The type 2 fuzzy device may be proposed to model a direct and rising uncertainty results. The expanded portion of Sort $1 \mathrm{FL}$ is referred to as Type $2 \mathrm{FL}$ and Type 2 FL is reduced to Type 1 FL with total ambiguity disappearance. [29], [30].

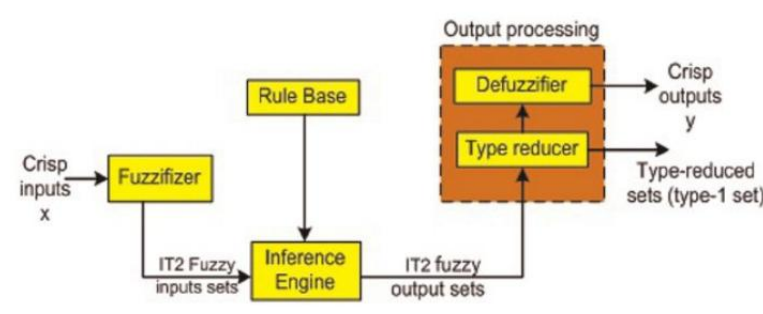

Figure VI Structure of type-2 fuzzy logic system

The user modelling framework, backed by FLS, is constructed in the sense of adaptive e-learning, causing simpler user interpretation with the developer [31]. FLSs are adopted to gage and measure learning and knowledge-related results, a lot of specifically analyze task targets, multiple evaluations of parameters, etc. In the development of AES, FLS may also be applied within the student modelling process, so that the content of the course is adapted to fit individual learning designs. Sorting a pair of FLSs can be a new type of fuzzy systems, familiar with the express numerical and language ambiguity, and could be projected to model a direct and those uncertainty outcomes. Extended type one American state sort a pair of American state offers a technique for dealing with numerical and linguistic ambiguity sources that exist in e-learning environments.

\section{B. NEURAL NETWORKS}

Visual information and major issue will indeed be carried out with the use of an oversized number of interlinking neurons or sections, referred to by anyone as a man-made neural network (ANN). Specifically, the model human behavior due to various their capacity to a method and to produce advanced information [8]. ANNs that are thought to be a good mechanism to uncover difficulties, and especially in the world of science, further contribute towards the improvement of tutorials explicitly throughout the sense of adaptation e-learning.

Chaplot, considering its new adaptive learning system design, supported ANN, that has the flexibility to manage multi-concept objects to accurately predict student results, and then choose to pursue the best issues tailored to the proficiency [32]. The anticipated method goes beyond the 2 limitations of the current AES; the lack of a scholar Model to deal with multi-concept issues and indeed the failure including its Domain Model to reliably select suitable issues for scholars to optimize knowledge acquisition through both the jobs of ANN.To address multi-concept issues, the projected development methodology of the Student Model or Learner Model is intended to leverage the related ANN,it does not presume any connection between inputs, contrary to earlier approaches.

Hmedna explains the methodology, but ANN is also accustomed to establishing the educational varieties of learners assisted by their behavior in wide Open Online Courses (MOOC).

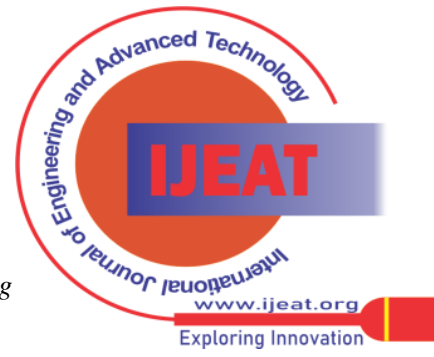


The forecast method encompasses a six (06) stage approach, a knowledge assortment, pre-processing, feature extraction, classification, learning profile, and adaptation.

A Neural Network can be used for the Classification Section (Supervised Classification) to discover and classify learning patterns. The system is often adapted to AES in distinctive individual learning designs that lead to the enhancement of the system's capabilities. The supervised classification technique used for this project could be a critical step wherever the messaging platform is always introduced to learners in an even way by their vocabulary. [33] Table 1 below illustrates comparison between fuzzy logic vs neural network.

Table 1 Comparison of Fuzzy logic vs Neural Network

\begin{tabular}{|l|l|}
\hline \multicolumn{1}{|c|}{ Fuzzy Logic } & \multicolumn{1}{c|}{ Neural Network } \\
\hline $\begin{array}{l}\text { Form of logic that would be } \\
\text { humanlike reasoning and }\end{array}$ & $\begin{array}{l}\text { Centered upon on human } \\
\text { brain's biological neural } \\
\text { networks for computing. }\end{array}$ \\
\hline $\begin{array}{l}\text { Allows to accomplish the } \\
\text { responsibilities of equally } \\
\text { pattern recognition and } \\
\text { classification problems }\end{array}$ & $\begin{array}{l}\text { Accelerates the functions of } \\
\text { estimation, identification, and } \\
\text { classification. }\end{array}$ \\
\hline $\begin{array}{l}\text { Methodology of the logic that is } \\
\text { like human cognitive and deals } \\
\text { with ambiguous and vague } \\
\text { knowledge. }\end{array}$ & $\begin{array}{l}\text { A device that is inspired by } \\
\text { biological neurons in the human } \\
\text { brain and thus can execute } \\
\text { computational task better. }\end{array}$ \\
\hline Knowledge can be available & Difficult to extract knowledge \\
\hline
\end{tabular}

\section{a. BAYESIAN NETWORKS}

A Bayesian Network (BN) can be a Direct Acyclic Graph (DAG) that describes the likelihood of dissemination associate in an extremely specific way that permits the diffusion of qualified probability as a correct illustration [34]. It is frequently used for the student modeling in smart educational systems.

Mangalwede and Rao have developed an e-learning framework when you are looking for comfortable and integrated learner evaluation module which implements customized content provision with case-based reasoning and BN. A lead to a paradigm for a particular course area unit thought about where the query area unit was divided into three groups as basic, moderate, and troublesome.

A queries square measure organized in an autoregressive model wherever the probabilistic connection between the two (02) sequential issues area unit captured exploitation BN. Such an approach seeks to authenticate the essential comprehension and skill of both a learner when this incentive is to never raise a problem that only the learner can respond effortlessly [35].

\section{b. GENETIC ALGORITHMS}

Genetic Algorithms (GA) Area Unit Optimization Algorithms supported Charles Darwin's theory of species evolution, wherever the goal is to hunt AN extreme of performance outlined in the field of information [36]. In conformity with the Davis (1991), optimization for the process is carried out in four (04) phases: low-level formatting. Selection, crossover, mutation [37]. Bhaskar has planned a GA mainly based reconciling learning method for context-aware eLearning [38]. The learning scheme invention algorithm is supposed genetically since the background parameter values of the different learners are limitations that need to be satisfied in the generation of the learning method. Relative to the that same method suggested by Huang.

\section{CONCLUSION}

The theory of adaptive e-learning exemplifies the process of learning from one learner differs from the other. The creation of realistic student models and profiles by modeling student personality traits, expertise levels are essential in the development of even an adaptable educational process.

Research analysis seems to have an improvement in the adaptation of Fuzzy Logic and the implementation of Artificial Neural Networks. Usage of Bayesian Networks to build a flipped classroom paradigm to fix the hesitancy of learning.

The Neural Network Approach Extraction Function can also be regarded as a significant technique to be used in the development of the Adaptation Model. Further research can be conducted out along with way when an adaptive eLearning system can be developed using ANN.

\section{ACKNOWLEDHEMENT}

Author thankful to Dr.Chamli Pushpakumara Faculty of Computing and Technology, University of Kelaniya .

\section{REFERANCES}

1. D. M. A. Khamis, "Adaptive e-Learning Environment Systems and Technologies," p. 41.

2. S. Lee, "Automated Defect Recognition Method by Using Digital Image Processing," p. 8.

3. H. D. Surjono, "The Design of Adaptive E-Learning System based on Student's Learning Styles," vol. 2, p. 4, 2011

4. R. Mahajan, "Web Usage Mining for Building an Adaptive e-Learning Site: A Case Study,” Int. J. E-Educ. E-Bus. E-Manag. E-Learn., vol. 4, no. 4, 2014, doi: 10.7763/IJEEEE. 2014.V4.343.

5. D. Bhawna and A. Abdalla, "Adaptive eLearning System: Conceptual Framework for Personalized Study Environment springerprofessional.de."

https://www.springerprofessional.de/en/adaptive-elearning-system-co nceptual-framework-for-personalized-/17177230 (accessed Nov. 06, 2019).

6. P. Brusilovsky and C. Peylo, "Adaptive and Intelligent Web-based Educational Systems," p. 14.

7. V. J. Shute and D. Zapata-Rivera, "Adaptive Educational Systems," in Adaptive Technologies for Training and Education, P. J. Durlach and A. M. Lesgold, Eds. Cambridge: Cambridge University Press, 2012, pp. 7-27.

8. E. Frías-Martínez, G. Magoulas, S. Chen, and R. Macredie, "Recent Soft Computing Approaches to User Modeling in Adaptive Hypermedia," in Adaptive Hypermedia and Adaptive Web-Based Systems, vol. 3137, P. M. E. De Bra and W. Nejdl, Eds. Berlin, Heidelberg: Springer Berlin Heidelberg, 2004, pp. 104-114.

9. N. Radwan, "An Adaptive Learning Management System Based on Learner's Learning Style," vol. 3, no. 4, p. 7, 2014.

10. V. Esichaikul, S. Lamnoi, and C. Bechter, "Student Modelling in Adaptive E-Learning Systems," p. 14.

11. K. Colchester, H. Hagras, D. Alghazzawi, and G. Aldabbagh, "A Survey of Artificial Intelligence Techniques Employed for Adaptive Educational Systems within E-Learning Platforms," J. Artif. Intell. Soft Comput. Res., vol. 7, no. 1, pp. 47-64, Jan. 2017, doi: 10.1515/jaiscr-2017-0004.

12. "The maturing of the MOOC: literature review of massive open online courses and other forms of online distance learning," p. 123.

13. A. Mustapha, S. H. Muhammad, and A. S. Salahudeen, "Massive Open Online Courses: A Success of Cloud Computing in Education," p. 11.

14. D. F. O. Onah, J. Sinclair, and R. Boyatt, "DROPOUT RATES OF MASSIVE OPEN ONLINE COURSES: BEHAVIOURAL PATTERNS," p. 10

Published By:

Blue Eyes Intelligence Engineering

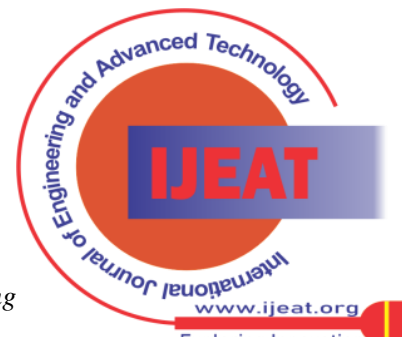




\section{A Review: Artificial Intelligent Approach for Enhancing Adaptability in an Adaptive E-Learning Environment}

15. "Educational Technology \& Society," p. 17.

16. S. Fauvel and H. Yu, "A Survey on Artificial Intelligence and Data Mining for MOOCs," p. 46.

17. Y. J. Dori and J. Belcher, "How Does Technology-Enabled Active Learning Affect Undergraduate Students' Understanding of Electromagnetism Concepts?," J. Learn. Sci., vol. 14, no. 2, pp. 243-279, Apr. 2005, doi: 10.1207/s15327809jls1402_3.

18. C. Romero, J. R. Romero, and S. Ventura, "A Survey on Pre-Processing Educational Data," in Educational Data Mining, vol. 524, A. Peña-Ayala, Ed. Cham: Springer International Publishing, 2014, pp. 29-64.

19. S. K. Mohamad and Z. Tasir, "Educational Data Mining: A Review," Procedia - Soc. Behav. Sci., vol. 97, pp. 320-324, Nov. 2013, doi: 10.1016/j.sbspro.2013.10.240.

20. A. Peña-Ayala, "Educational data mining: A survey and a data mining-based analysis of recent works," Expert Syst. Appl., vol. 41, no. 4, pp. 1432-1462, Mar. 2014, doi: 10.1016/j.eswa.2013.08.042.

21. F. Essalmi, L. J. B. Ayed, M. Jemni, Kinshuk, and S. Graf, "A fully personalization strategy of E-learning scenarios," Comput. Hum. Behav., vol. 26, no. 4, pp. 581-591, Jul. 2010, doi: 10.1016/j.chb.2009.12.010.

22. F. J. T. Moreno and M. J. G. Moreno, "Using Bayesian Networks in the Global Adaptive E-learning Process," p. 4.

23. H. J. Cha, Y. S. Kim, S. H. Park, T. B. Yoon, Y. M. Jung, and J.-H. Lee, "Learning Styles Diagnosis Based on User Interface Behaviors for the Customization of Learning Interfaces in an Intelligent Tutoring System," in Intelligent Tutoring Systems, vol. 4053, M. Ikeda, K. D. Ashley, and T.-W. Chan, Eds. Berlin, Heidelberg: Springer Berlin Heidelberg, 2006, pp. 513-524.

24. Dongming $\mathrm{Xu}$, Huaiqing Wang, and Kaile $\mathrm{Su}$, "Intelligent student profiling with fuzzy models," in Proceedings of the 35th Annual Hawaii International Conference on System Sciences, Big Island, HI, USA, 2002, p. 8, doi: 10.1109/HICSS.2002.994005.

25. A.-R. Ahmad, O. Basir, and K. Hassanein, "Adaptive User Interfaces for Intelligent E-Learning: Issues and Trends," p. 10.

26. J. M. Mendel, "Fuzzy logic systems for engineering: a tutorial," Proc. IEEE, vol. 83, no. 3, pp. 345-377, Mar. 1995, doi: 10.1109/5.364485.

27. M. Trabia, "Overview of Fuzzy Logic," p. 24.

28. K. Almohammadi and H. Hagras, "An adaptive fuzzy logic-based system for improved knowledge delivery within intelligent E-Learning platforms," in 2013 IEEE International Conference on Fuzzy Systems (FUZZ-IEEE), Hyderabad, India, Jul. 2013, pp. 1-8, doi: 10.1109/FUZZ-IEEE.2013.6622350.

29. F. Gomide, "Uncertain rule-based fuzzy logic systems: introduction and new directions," Fuzzy Sets Syst., vol. 133, no. 1, pp. 133-135, Jan. 2003, doi: 10.1016/S0165-0114(02)00359-7.

30. M. Shahriari-kahkeshi and S. Rahmani, "Adaptive interval type-2 fuzzy dynamic surface control for uncertain nonlinear systems with unknown asymmetric dead-zone input:," Trans. Inst. Meas. Control, May 2018, doi: 10.1177/0142331218765618.

31. A. Jameson, "Numerical uncertainty management in user and student modeling: An overview of systems and issues," User Model. User-Adapt. Interact., vol. 5, no. 3-4, pp. 193-251, 1996, doi: 10.1007/BF01126111.

32. D. S. Chaplot, E. Rhim, and J. Kim, "Personalized Adaptive Learning using Neural Networks," in Proceedings of the Third (2016) ACM Conference on Learning @ Scale - L@S '16, Edinburgh, Scotland, UK, 2016, pp. 165-168, doi: 10.1145/2876034.2893397.

33. B. HMEDNA, A. E. Mezouary, O. Baz, and D. Mammass, "Identifying and tracking learning styles in MOOCs: A neural networks approach." Feb. 02, 2017, [Online]. Available: http://www.ijias.issr-journals.org/.

34. H. Gamboa and A. Fred, "DESIGNING INTELLIGENT TUTORING SYSTEMS: A BAYESIAN APPROACH."

35. S. R. Mangalwede and Dr. D. H. Rao, "Application of Bayesian Networks for Learner Assessment in E-Learning Systems," Int. J. Comput. Appl., vol. 4, no. 4, pp. 23-27, Jul. 2010, doi: 10.5120/816-1157.

36. S. Azough, M. Bellafkih, and E. H. Bouyakhf, "Adaptive E-learning using Genetic Algorithms," p. 8, 2010

37. A. Drigas, K. Argyri, and J. Vrettaros, "Decade Review 1999-2009 Artificial Intelligence Te.pdf."

38. M. Bhaskar, M. M. Das, D. T. Chithralekha, and D. S. Sivasatya, "Genetic Algorithm Based Adaptive Learning Scheme Generation For Context Aware E-Learning," vol. 02, no. 04, p. 9, 2010.

39. A. S. Huang et al., "Visual Odometry and Mapping for Autonomous Flight Using an RGB-D Camera," in Robotics Research, vol. 100, H. I. Christensen and O. Khatib, Eds. Cham: Springer International Publishing, 2017, pp. 235-252.

\section{AUTHORS PROFILE}

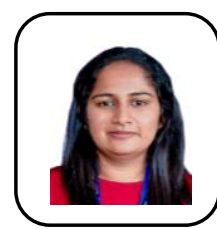

M.P.L. Perera, is working as a Temporary Lecturer, Faculty of Computing and Technology, University of Kelaniya ,Sri Lanka .She has completed her bachelors from General Sir John Kotelawala Defence University Sri Lanka in 2019. Her area of research includes Education, Brain Computer interface, Artificial Intelligence and GIS. She has published several conference papers in the National and International as well as one journal in International.
Published By:

Blue Eyes Intelligence Engineering

\& Sciences Publication

(c) Copyright: All rights reserved.

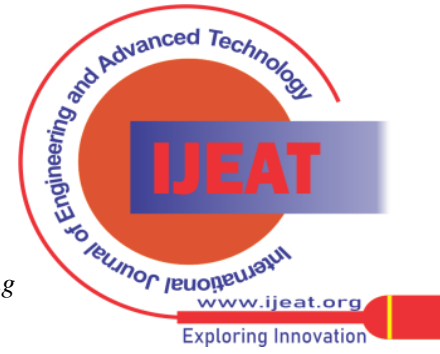

